\title{
UMA BREVE INCURSÃO PELA FALA CULTA RECIFENSE: VOGAIS MÉDIAS PRETÔNICAS À LUZ DA SOCIOLINGUÍSTICA
}

\author{
Márcia Cristina de Brito Rumeu*
}

Resumo: Neste trabalho, analisa-se a variação das vogais médias pretônicas na fala culta de Recife com base nos dados do Projeto NURC. Adotam-se os pressupostos de análise da teoria da variação laboviana, visando à depreensão dos contextos estruturais e sociais favorecedores à aplicação das regras variáveis de abaixamento e de elevação dos segmentos médios vocálicos. Na fala recifense, além de os resultados apontarem para a tendência de abertura das pretônicas médias, também evidenciam as mulheres jovens com uma maior produtividade da regra variável de elevação vocálica, assumindo um comportamento linguístico mais inovador.

Palavras-chave: Vogais médias pretônicas; abaixamento vocálico; elevação vocálica; variação linguística.

Abstract: This paper will analyze the variation in pretonic mid vowels in the standard speech of Recife, based on data from the NURC Project. The analysis will follow the assumptions of the Labovian variation theory, considering structural and social contexts that favor the use of the variable rules of lowering and raising vowels. In the speech of Recife, results point to both a tendency to open pretonic mid vowels as well as to young women producing higher vowels, suggesting a more innovative linguistic behavior.

Keywords: Pretonic mid vowels; vowel lowering; vowel raising; linguistic variation.

* Universidade Federal de Minas Gerais. 


\section{Considerações iniciais}

Nascentes (1953) considera as realizações das vogais médias pretônicas como parâmetros para o estabelecimento das diferenças dialetais do português brasileiro (doravante PB), admitindo que, nos falares do norte, prioriza-se a realização aberta das vogais médias, ao passo que, nos falares do sul, prefere-se a realização fechada das médias pretônicas. Com base nessa percepção de Nascentes, justifica-se uma análise sociolinguística das vogais médias pretônicas voltada especificamente para a fala de uma capital nordestina, buscando, assim, contribuir para a compreensão da heterogênea realidade fonológica do PB. Neste sentido, volta-se o foco deste estudo para a descrição dos contextos estruturais e sociais que condicionam a aplicação das regras variáveis de abaixamento e de elevação das vogais médias pretônicas na fala culta de Recife.

O princípio da variação que rege as línguas humanas é o que impulsiona as vogais médias pretônicas a poderem se realizar ${ }^{1}$ como abertas, em $m[\varepsilon]$ lbor e $c[\curvearrowright] l e ́ g i o$, como fechadas, em $m$ [e]lbor e $c[0]$ légio, ou como altas, em $m[\mathrm{i}]$ lbor e $c[\mathrm{u}]$ légio no PB. Essas realizações flutuantes podem ter seus contextos estruturais e sociais quantitativamente sistematizados, se analisadas à luz da Teoria da Variação laboviana (WEINREICH, LABOV \& HERZOG, 1968; LABOV, 2008 [1972]). Com base nessa perspectiva teórica, pretende-se descrever a sistematicidade de aplicação das regras variáveis de abaixamento e de elevação das vogais médias pretônicas na fala culta de Recife.

Este texto apresenta-se dividido em cinco seções. Nas considerações iniciais, expõe-se o tipo de abordagem atribuída às regras variáveis de abaixamento e de elevação das vogais pretônicas médias na fala culta recifense. Na próxima seção, apresenta-se o

\footnotetext{
${ }^{1}$ Emprega-se a expressão vogais médias de um ponto de vista fonêmico ao longo deste texto.
} 
corpus e esclarecem-se os pressupostos teórico-metodológicos que fundamentam esta análise à luz da teoria da variação de orientação laboviana. A seguir, divulgam-se e discutem-se os resultados desta análise quantitativa em relação aos fatores estruturais propulsores das regras variáveis de abaixamento e elevação das vogais médias pretônicas. Na sequência, passa-se à análise da relação entre a aplicabilidade dessas regras variáveis (abaixamento e elevação das médias pretônicas) e a influência do contexto social expresso através do cruzamento das categorias sociais gênero e faixa etária dos falantes cultos recifenses. Por fim, tecem-se algumas considerações sobre as vogais médias pretônicas na fala recifense, relacionadoas aos resultados de outros estudos com base na língua falada das regiões nordeste, sudeste e sul do Brasil.

\section{O corpus e a metodologia}

Com o intuito de depreender a aplicabilidade das regras de abaixamento e de elevação das pretônicas médias, explicitamse os contextos linguístico e social que podem conduzir a implementação de tais regras variáveis na fala culta recifense. Foram registrados 600 segmentos vocálicos médios em posição pretônica: 270 segmentos da vogal oral média anterior, 279 segmentos da vogal oral média posterior, 30 segmentos de vogal nasal anterior e 21 segmentos da vogal nasal posterior. Extraíramse os dados de inquéritos do tipo DID -Diálogo entre Informante e Documentador - datados do final da década de 70 do século XX - pertencentes ao acervo sonoro do Projeto NURC-Recife (Norma Urbana Oral Culta - Recife). Essas seiscentas ocorrências foram provenientes de seis entrevistas, subdivididas em três do gênero feminino e três do gênero masculino e distribuídas por três faixas etárias - de 25 a 35 anos, de 36 a 55 anos e de 56 anos em diante.

Posteriormente, aos 600 dados atribuiu-se uma codificação com o intuito de depreender os contextos estruturais e sociais que influenciaram o abaixamento e a elevação dos fonemas vocálicos 
orais /e/ e /o/ em posição pretônica, numa análise binomial cujas variáveis dependentes são $[\varepsilon, 0]$ e $[i, u]$, respectivamente. Tomando como parâmetro as variáveis testadas por Yacovenco (1993) para as pretônicas médias orais da fala culta carioca, os contextos estruturais testados foram os seguintes: (1) o timbre da vogal pretônica - pretônicas orais anteriores $[\mathrm{e}] /[\varepsilon]$, pretônicas orais posteriores $[0] /[0]$, pretônicas nasais anteriores $[\tilde{1}] /[\tilde{e}]$ e as pretônicas nasais posteriores $[\tilde{\mathrm{u}}] /[\tilde{o}]$; (2) a distância da vogal pretônica em relação à tônica - na possibilidade de existência da pretônica 1 (frequência), pretônica 2 (defender), pretônica 3 (odontológica) e pretônica 4 (polinização); (3) o timbre do segmento tônico - vogais altas, médias, baixas e ditongos $;^{2}$ (4) o timbre da pretônica subsequente - na eventualidade de a distância da vogal pretônica em relação à tônica ser diferente de 1, observase se o segmento pretônico subsequente ao tônico é uma vogal alta, baixa, média ou um ditongo; (5) o modo de articulação do segmento precedente ao pretônico - oclusiva, fricativa, nasal, grupo consonântico, vibrante, lateral, vogal e zero fonético; (6) o modo de articulação do segmento subsequente ao segmento pretônico - oclusiva, fricativa, nasal, grupo consonântico, vibrante, lateral e vogal; (7) o ponto de articulação do segmento precedente ao segmento pretônico - labial, alveolar, palatal, velar; e (8) a estrutura da sílaba que comporta o segmento pretônico em análise - V (elite), CV (período), VC (escolar), CVC (servir), CCV (frequência), CVV (violência), VV (maioria). As hipóteses que movem essas variáveis estruturais podem ser sintetizadas da seguinte forma: espera-se que a elevação vocálica seja favorecida pela existência de uma vogal alta ou baixa na sílaba tônica (LEITE

\footnotetext{
${ }^{2}$ Ainda que o contexto de ditongo esteja elencado como um único fator cujo grupo é o timbre de um único segmento vocálico tônico, essa opção metodológica foi assumida com o intuito de controlar se o contexto de ditongo (dois segmentos vocálicos numa mesma sílaba) influenciaria ou não a produtividade das regras variáveis em análise.
} 
\& CALLOU, 2002, p. 41), ao passo que, em relação ao abaixamento vocálico, acredita-se que seja condicionado pelos contextos estruturais que desfavorecem a elevação vocálica. O ponto de articulação dos segmentos consonantais circunvizinhos também é um fator propulsor da elevação vocálica no PB (LEITE \& CALLOU, 2002, p. 41). Tanto o segmento palatal $([\lambda]$, grafado $l h)$ tende a promover a elevacão das pretônicas médias anterior e posterior $(m[\mathrm{i}]$ lhor, $c[\mathrm{u}]$ lher $)$, quanto os segmentos consonantais labiais ([p]/[b], [f]/[v], [m]) tendem a incentivar a elevação da pretônica média posterior como, por exemplo, em $m[\mathrm{u}]$ leque e $b[\mathrm{u}]$ neca. $\mathrm{O}$ contexto social está representado por dois grupos de fatores: (1) o gênero e (2) a faixa etária dos informantes.

A quantificação dos dados deu-se através do pacote de programas VARBRUL (VARiaBle RULe), conforme Sankoff (1988), que, além de calcular a frequência de uso das regras variáveis, é capaz de computar, através de índices de pesos relativos, a contribuição dos contextos estruturais e sociais para a aplicação das regras variáveis em análise. Considerando que o grau de significância de cada grupo de fatores evidencia a contribuição de cada fator para a aplicação da regra variável, assume-se que níveis de significância próximos ao valor .000 indicam a relevância do grupo de fatores para a aplicabilidade da regra. Ao analisar a seleção estatística feita pelo programa computacional, interpreta-se .50 como resultado neutro; índices probabilísticos abaixo e acima desse valor (.50) são considerados como inibidores e favorecedores, respectivamente, da aplicação das regras variáveis em análise. Para a descrição dos percentuais e pesos relativos dos condicionamentos linguísticos e extralinguísticos, resguardou-se a ordem em que foram selecionados pelo VARBRUL. Passa-se, a seguir, à exposição dos resultados acerca da aplicabilidade das regras variáveis de abaixamento e de elevação das vogais médias pretônicas na fala culta recifense. 


\section{As vogais médias pretônicas na fala culta de Recife: apresentação dos resultados}

Considerando a expectativa de distintas realizações das vogais médias em posição pretônica, apresentam-se, na distribuição geral dos dados, os resultados percentuais de uma análise ternária tanto para as médias anteriores [e, $\varepsilon, \mathrm{i}]$, quanto para as médias posteriores $[\mathrm{o}, 0, \mathrm{u}]$. A quantificação dos segmentos vocálicos pretônicos orais médios na fala culta recifense confirmou o sistema de variação no $\mathrm{PB}$, como é possível observar através da Tabela $1 .^{3}$

\section{TABELA 1}

Quadro geral das realizações das vogais médias orais em posição pretônica na fala culta recifense

\begin{tabular}{c|c|c|c|c|c}
\hline $\begin{array}{c}\text { Realizações } \\
\text { do segmento } \\
\text { vocálico oral } \\
\text { médio } \\
\text { anterior } \\
\text { em posição } \\
\text { pretônica }\end{array}$ & Ocorrências & $\begin{array}{c}\text { Frequências } \\
\text { (\%) }\end{array}$ & $\begin{array}{c}\text { Realizações } \\
\text { do segmento } \\
\text { vocálico oral } \\
\text { médio } \\
\text { posterior } \\
\text { em posição } \\
\text { pretônica }\end{array}$ & Ocorrências & $\begin{array}{c}\text { Frequências } \\
\text { (\%) }\end{array}$ \\
\hline$[\varepsilon]$ & $132 / 300$ & $44 \%$ & {$[0]$} & $126 / 300$ & $42 \%$ \\
{$[i$ i ] } & $73 / 300$ & $24 \%$ & {$[$ o ] } & $78 / 300$ & $26 \%$ \\
{$[$ e ] } & $65 / 300$ & $22 \%$ & {$[$ u ] } & $75 / 300$ & $25 \%$ \\
\hline Totais & $270 / 300$ & $90 \%$ & Totais & $279 / 300$ & $93 \%$ \\
\hline
\end{tabular}

Ao analisar o quadro geral exposto na Tabela 1, observa uma distribuição equilibrada entre o número de ocorrências de vogais médias anteriores e posteriores, tendo em vista as trezentas ocorrências para cada variável em análise. No que se refere à realização das pretônicas médias orais, observou-se a aplicação da regra de abaixamento vocálico como a estratégia preferida pelos falantes cultos

\footnotetext{
${ }^{3}$ Nesta tabela, apresentam-se as frequências de uso para as três variantes das vogais médias pretônicas anteriores $[\mathrm{e}, \varepsilon, \mathrm{i}]$ e posteriores $[\mathrm{o}, \mathrm{\jmath}, \mathrm{u}]$, expondo um resultado distribucional em termos de índices percentuais brutos da produtividade dessas variantes vocálicas na fala culta recifense.
} 
recifenses, com percentuais de uso de 44\% e 42\%, para as médias anteriores e posteriores, respectivamente. A elevação e a manutenção vocálicas apresentam frequências de uso de $24 \%$ e $22 \%$, para as anteriores, e $25 \%$ e $26 \%$, para as posteriores, respectivamente.

Em relação aos segmentos nasais médios pretônicos, verificou-se a elevação ou a manutenção, nunca o abaixamento vocálico. O comportamento das nasais se mostrou simétrico em relação às regras variáveis de elevação e de manutenção. No que diz respeito às médias nasais anteriores, tem-se 14 ocorrências de [ĩ] (4,6\%) em 300 dados e 16 ocorrências de [ẽ] (5,3\%) em 300 dados no corpus em análise. Foi categórica a manutenção vocálica entre as pretônicas médias nasais posteriores, pois, em 21 dados de um total de 300, computaram-se as 21 ocorrências de [õ] (100\%).

Redirecionando o foco deste estudo exclusivamente para a análise das pretônicas médias orais com a exclusão dos dados dos segmentos nasais médios e com a supressão dos dados em que não houve variação entre as pretônicas médias orais (trata-se da retirada dos dados de knockouts detectados pelo VARBRUL), passa-se à apresentação dos resultados relacionados à aplicação das regras variáveis de abaixamento e de elevação de tais segmentos vocálicos anteriores e posteriores na fala culta recifense. Neste estudo, todos os pesos relativos apresentados são resultados de uma metodologia binária de tratamento das variantes vocálicas (binomial up and down) tanto para a regra variável de abaixamento vocálico $([\varepsilon, \diamond])$, quanto para a regra variável de alteamento vocálico ([i, u]).

\subsection{A regra variável de abaixamento das vogais médias orais anteriores}

O abaixamento vocálico tomando como valor de aplicação a realização aberta das pretônicas médias orais anteriores revelou os índices percentual e probabilístico de $49 \%$ e .49, respectivamente, para a aplicação dessa regra variável. Os contextos estruturais favorecedores à aplicação de tal regra foram o timbre do segmento tônico, o ponto de articulação do segmento precedente à pretônica 
e o modo de articulação do segmento subsequente à pretônica, conforme se verifica, respectivamente, nas Tabelas 2,3 e 4 .

\section{TABELA 2}

Abaixamento das pretônicas médias orais anteriores: timbre do segmento tônico

\begin{tabular}{c|c|c|c}
\hline $\begin{array}{c}\text { Timbre do segmento tônico } \\
\text { (Nivel de significância: .000) }\end{array}$ & Ocorrências & $\begin{array}{c}\text { Frequências } \\
\text { (\%) }\end{array}$ & P.R. $^{4}$ \\
\hline Vogal baixa & $39 / 58$ & $67 \%$ & .72 \\
Vogal média & $56 / 101$ & $55 \%$ & .56 \\
Ditongo & $09 / 20$ & $45 \%$ & .41 \\
Vogal alta & $28 / 91$ & $31 \%$ & .31 \\
\hline
\end{tabular}

Com base na análise da Tabela 2 , constata-se que as vogais baixas e médias na sílaba acentuada, conforme é possível observar nos vocábulos $z[\varepsilon]$ lar e $t[\varepsilon]$ rreno, respectivamente, representam os contextos estruturais que propiciaram o abaixamento das pretônicas médias anteriores.

\section{TABELA 3}

Abaixamento das pretônicas médias orais anteriores:

ponto de articulação do segmento precedente à pretônica

\begin{tabular}{c|c|c|c}
\hline $\begin{array}{c}\text { Ponto de articulação do segmento } \\
\text { precedente à pretônica } \\
\text { (Nível de significância: .002) }\end{array}$ & Ocorrências & $\begin{array}{c}\text { Frequências } \\
\text { (\%) }\end{array}$ & P.R. \\
\hline Labial & $68 / 112$ & $61 \%$ & .62 \\
Alveolar & $47 / 104$ & $45 \%$ & .45 \\
Velar & $03 / 10$ & $30 \%$ & .37 \\
Palatal & $02 / 14$ & $14 \%$ & .11 \\
\hline
\end{tabular}

Observa-se, na Tabela 3, que os segmentos consonantais labiais que precederam a vogal média pretônica - cf. sup $[\varepsilon]$ rior, $p[\varepsilon]$ rduram, $p[\varepsilon]$ rdida, $m[\varepsilon]$ rcúrio - tenderam a favorecer o abaixamento das pretônicas médias anteriores.

\footnotetext{
${ }^{4}$ Leia-se "P.R." como "peso relativo" em todas as tabelas expostas neste texto.
} 
TABELA 4

Abaixamento das médias orais anteriores: modo de articulação do segmento subsequente à pretônica

\begin{tabular}{c|c|c|c}
\hline $\begin{array}{c}\text { Modo de articulação do segmento } \\
\text { subsequente à pretônica } \\
\text { (Nível de significância: .014) }\end{array}$ & Ocorrências & $\begin{array}{c}\text { Frequências } \\
\text { (\%) }\end{array}$ & P.R. \\
\hline Lateral & $14 / 22$ & $64 \%$ & .61 \\
Vibrante & $44 / 72$ & $61 \%$ & .62 \\
Oclusiva & $23 / 50$ & $46 \%$ & .48 \\
Fricativa & $45 / 101$ & $45 \%$ & .48 \\
Grupo consonântico & $03 / 07$ & $43 \%$ & .41 \\
Nasal & $02 / 15$ & $13 \%$ & .12 \\
\hline
\end{tabular}

Verifica-se, conforme a análise da Tabela 4 , que os segmentos consonantais laterais e vibrantes subsequentes à

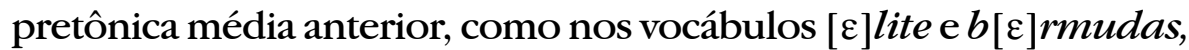
respectivamente, tenderam a favorecer o abaixamento vocálico.

Prossegue-se a análise com a exposição dos condicionamentos fonéticos para o abaixamento das pretônicas médias orais posteriores, na fala culta recifense.

\subsection{A regra variável de abaixamento das vogais médias orais posteriores}

Ao analisar a realização aberta das pretônicas médias orais posteriores, constata-se que são, respectivamente, de $45 \%$ e .46 os indicadores percentual e probabilístico de aplicação do abaixamento vocálico. Apresentam-se, na sequência, as frequências de uso e os índices probabilísticos vinculados especificamente timbre do segmento tônico e ao modo de articulação do segmento precedente à pretônica selecionados como os contextos estruturais propulsores do abaixamento da pretônica média oral posterior, conforme se observa, respectivamente, nas Tabelas 5 e 6 . 
TABELA 5

Abaixamento das médias orais posteriores: timbre do segmento tônico

\begin{tabular}{c|c|c|c}
\hline $\begin{array}{c}\text { Timbre do segmento tônico } \\
\text { (Nível de significância: .005) }\end{array}$ & Ocorrências & $\begin{array}{c}\text { Frequências } \\
\text { (\%) }\end{array}$ & P.R. \\
\hline Vogal baixa & $48 / 76$ & $63 \%$ & .69 \\
Ditongo & $10 / 23$ & $43 \%$ & .44 \\
Vogal média & $43 / 111$ & $39 \%$ & .43 \\
Vogal alta & $25 / 69$ & $36 \%$ & .40 \\
\hline
\end{tabular}

A interpretação da Tabela 5 permite entender que as vogais baixas, em posição tônica, como nos itens lexicais $b$ [॰]tânicas e lit[o]rânea, revelaram-se contextos estruturais propiciadores do abaixamento da pretônica média posterior.

TABELA 6

Abaixamento das médias orais posteriores:

modo de articulação do segmento precedente à pretônica

\begin{tabular}{c|c|c|c}
\hline $\begin{array}{c}\text { Modo de articulação do segmento } \\
\text { precedente à pretônica } \\
\text { (Nivel de significância: :005) }\end{array}$ & Ocorrências & $\begin{array}{c}\text { Frequências } \\
\text { (\%) }\end{array}$ & P.R. \\
\hline Grupo consonântico & $25 / 36$ & $69 \%$ & .75 \\
Zero & $16 / 24$ & $67 \%$ & .70 \\
Nasal & $21 / 43$ & $49 \%$ & .54 \\
Fricativa & $15 / 33$ & $45 \%$ & .51 \\
Vogal & $02 / 05$ & $40 \%$ & .47 \\
Oclusiva & $46 / 134$ & $34 \%$ & .39 \\
Lateral & $01 / 03$ & $33 \%$ & .36 \\
\hline
\end{tabular}

Com base na Tabela 6, observa-se que os grupos consonânticos (pr[o]cura), a inexistência de segmentos (ø b[॰]rrível, ø [०]linda), os segmentos nasais (n[॰]civos) e os segmentos fricativos (dev[0]lutos) precedentes à pretônica média oral posterior mostraram-se como contextos estruturais favorecedores á aplicação da regra de abaixamento vocálico.

Em síntese, têm-se, com relação ao abaixamento das pretônicas médias orais anteriores, os seguintes contextos estruturais como os impulsionadores da aplicação dessa regra variável. Para a vogal média anterior, os fatores que se mostraram 
mais atuantes foram o timbre do segmento tônico (vogal baixa), o ponto de articulação do segmento precedente à pretônica (labial) e o modo de articulação do segmento subsequente à pretônica (lateral ou vibrante). Para a vogal média posterior, temse o timbre do segmento tônico (vogal baixa) e o modo de articulação do segmento precedente à pretônica (grupo consonântico, zero, nasal ou fricativa) como os condicionamentos da aplicação da regra variável em análise na fala culta recifense.

Expõem-se, a seguir, os contextos estruturais propulsores da aplicação da regra variável de elevação das pretônicas médias orais na fala culta recifense.

\subsection{A regra variável de elevação das vogais médias orais anteriores}

O estudo da elevação vocálica evidenciou os índices percentuais e probabilístico de $27 \%$ e .28 para a aplicação dessa regra variável. Dois contextos estruturais - o timbre do segmento tônico, o ponto de articulação do segmento precedente ao pretônico - e um contexto social - o gênero dos informantes condicionaram as pretônicas médias orais anteriores à elevação vocálica, conforme é possível observar, respectivamente, nas Tabelas 7,8 e 9 .

\section{TABELA 7}

Elevação das médias orais anteriores: timbre do segmento tônico

\begin{tabular}{c|c|c|c}
\hline $\begin{array}{c}\text { Timbre do segmento tônico } \\
\text { (Nivel de significância: .000) }\end{array}$ & Ocorrências & $\begin{array}{c}\text { Frequências } \\
\text { (\%) }\end{array}$ & P.R. \\
\hline Alta & $40 / 91$ & $44 \%$ & .75 \\
Ditongo & $08 / 20$ & $40 \%$ & .76 \\
Média & $19 / 101$ & $19 \%$ & .44 \\
Baixa & $06 / 58$ & $10 \%$ & .16 \\
\hline
\end{tabular}

Verifica-se, na Tabela 7 , que as vogais altas - $m[\mathrm{i}]$ nina, $R[\mathrm{i}]$ cife - e os ditongos $-l[\mathrm{i}] \tilde{a} o, b[\mathrm{i}]$ liscão, $s[\mathrm{i}]$ ria - apresentam-se como segmentos vocálicos que, em posição tônica, favoreceram a elevação da pretônica média anterior. 
TABELA 8

Elevação das médias orais anteriores:

ponto de articulação do segmento precedente à pretônica

\begin{tabular}{c|c|c|c}
\hline $\begin{array}{c}\text { Ponto de articulação do segmento } \\
\text { precedente à pretônica } \\
\text { (Nível de Significância: .000) }\end{array}$ & Ocorrências & $\begin{array}{c}\text { Frequências } \\
\text { (\%) }\end{array}$ & P.R. \\
\hline Palatal & $11 / 13$ & $79 \%$ & .97 \\
Velar & $03 / 10$ & $30 \%$ & .46 \\
Alveolar & $23 / 104$ & $22 \%$ & .47 \\
Labial & $23 / 112$ & $21 \%$ & .42 \\
\hline
\end{tabular}

Conforme a análise da Tabela 8 , observa-se que os segmentos palatais que precedem à vogal média anterior propiciaram à elevação vocálica, como se verifica nos vocábulos $d[\mathrm{i}]$ scarga, $d[\mathrm{i}]$ sastre e tat $[\mathrm{i}]$ ar. Atente-se para o fato de que é quase categórico (.97) o nível de elevação da pretônica média anterior precedida por segmentos palatais.

TABELA 9

Elevação das médias orais anteriores

em relação ao gênero (sexo) dos falantes recifenses

\begin{tabular}{c|c|c|c}
\hline $\begin{array}{c}\text { Gênero (sexo) } \\
\text { (Nivel de Significância: :032) }\end{array}$ & Ocorrências & $\begin{array}{c}\text { Frequências } \\
\text { (\%) }\end{array}$ & P.R. \\
\hline Feminino & $28 / 133$ & $33 \%$ & .61 \\
Masculino & $45 / 137$ & $21 \%$ & .39 \\
\hline
\end{tabular}

Com base na Tabela 9, observa-se que as mulheres recifenses tenderam a elevar a pretônica média anterior.

Prosseguindo a análise proposta, passa-se à exposição dos condicionamentos da regra de elevação das pretônicas médias posteriores.

\subsection{A regra variável de elevação das vogais médias orais posteriores}

Ao examinar a elevação vocálica, considerando como valor de aplicação a realização alta das pretônicas médias orais posteriores, constata-se que são de $27 \%$ e .27 os índices percentual e probabilístico 
de aplicação da regra variável em análise. Quatro variáveis estruturais - o timbre do segmento tônico, o modo de articulação do segmento precedente à pretônica, o modo de articulação do segmento subsequente à pretônica, o ponto de articulação do segmento precedente à pretônica - e somente uma variável extralinguística - o gênero dos informantes - condicionaram a aplicação da regra de elevação das pretônicas médias orais posteriores. Descrevem-se, a seguir, os índices de elevação das pretônicas médias posteriores em relação aos condicionamentos da aplicação dessa regra variável, conforme se verifica, respectivamente, nas Tabelas 10 a 14 .

TABELA 10

Elevação das médias orais posteriores: timbre do segmento tônico

\begin{tabular}{c|c|c|c}
\hline $\begin{array}{c}\text { Timbre do segmento tônico } \\
\text { (Nível de Significância: .000) }\end{array}$ & Ocorrências & $\begin{array}{c}\text { Frequências } \\
\text { (\%) }\end{array}$ & P.R. \\
\hline Vogal alta & $32 / 69$ & $46 \%$ & .76 \\
Ditongo & $07 / 23$ & $30 \%$ & .75 \\
Vogal média & $32 / 111$ & $29 \%$ & .55 \\
Vogal baixa & $07 / 76$ & $05 \%$ & .15 \\
\hline
\end{tabular}

Constata-se, com base na Tabela 10, que as vogais altas (n[u]tícia), os ditongos (apr $[\mathrm{u}]$ veita) e as vogais médias (c[u]légio) em posição tônica são os segmentos vocálicos que propiciaram à elevação das pretônicas médias orais posteriores.

TABELA 11

Elevação das médias orais posteriores:

modo de articulação do segmento precedente à pretônica

\begin{tabular}{c|c|c|c}
\hline $\begin{array}{c}\text { Modo de articulação do segmento } \\
\text { precedente à pretônica } \\
\text { (Nível de Significância: .000) }\end{array}$ & Ocorrências & $\begin{array}{c}\text { Frequências } \\
\text { (\%) }\end{array}$ & P.R. \\
\hline Vogal & $02 / 05$ & $40 \%$ & .75 \\
Oclusiva & $52 / 134$ & $39 \%$ & .72 \\
Lateral & $01 / 03$ & $33 \%$ & .69 \\
Nasal & $10 / 43$ & $23 \%$ & .47 \\
Fricativa & $05 / 33$ & $15 \%$ & .45 \\
Zero & $02 / 24$ & $08 \%$ & .29 \\
Grupo consonântico & $02 / 36$ & $06 \%$ & .06 \\
\hline
\end{tabular}


As consoantes oclusivas, conforme se observa na Tabela 11, que precedem às médias posteriores em posição pretônica $p[\mathrm{u}]$ der, $b[\mathrm{u}]$ neco, $t[\mathrm{u}]$ mar, $d[\mathrm{u}]$ entes, desc $[\mathrm{u}]$ bertas, $g[\mathrm{u}]$ verno - favoreceram a aplicação da regra de elevação vocálica para as médias orais posteriores. O baixíssimo número de ocorrências das vogais (duas em cinco ocorrências) e das laterais (uma em três ocorrências) desautoriza a interpretação de tais contextos fonéticos com altos pesos relativos (.75 e .69, respectivamente) como condicionamentos estruturais para a aplicação da elevação vocálica.

\section{TABELA 12}

Elevação das médias orais posteriores:

modo de articulação do segmento subsequente à pretônica

\begin{tabular}{c|c|c|c}
\hline $\begin{array}{c}\text { Modo de articulação do segmento } \\
\text { subsequente à pretônica } \\
\text { (Nível de Significância: .006) }\end{array}$ & Ocorrências & $\begin{array}{c}\text { Frequências } \\
\text { (\%) }\end{array}$ & P.R. \\
\hline Fricativa & $14 / 36$ & $39 \%$ & .77 \\
Oclusiva & $19 / 64$ & $39 \%$ & .66 \\
Nasal & $16 / 41$ & $30 \%$ & .61 \\
Vibrante & $11 / 82$ & $13 \%$ & .34 \\
Lateral & $08 / 39$ & $21 \%$ & .29 \\
Grupo consonântico & $01 / 11$ & $09 \%$ & .16 \\
\hline
\end{tabular}

A análise da Tabela 12 permite entender que as fricativas, as oclusivas e as nasais subsequentes à vogal pretônica média oral posterior - como se observa, respectivamente, nos itens lexicais $[\mathrm{u}]$ velha, $m[\mathrm{u}]$ dernos e $c[\mathrm{u}] m e r$ - mostraram-se, para as médias orais posteriores, como os contextos propulsores da elevação vocálica na fala culta de Recife. 
TABELA 13

Elevação das médias orais posteriores:

ponto de articulação do segmento precedente à pretônica

\begin{tabular}{c|c|c|c}
\hline $\begin{array}{c}\text { Ponto de articulação do segmento } \\
\text { precedente à pretônica } \\
\text { (Nível de Significância: .125) }\end{array}$ & Ocorrências & $\begin{array}{c}\text { Frequências } \\
\mathbf{( \% )}\end{array}$ & P.R. \\
\hline Palatal & $01 / 04$ & $25 \%$ & .75 \\
Labial & $41 / 141$ & $29 \%$ & .61 \\
Velar & $21 / 57$ & $37 \%$ & .45 \\
Alveolar & $08 / 48$ & $17 \%$ & .23 \\
\hline
\end{tabular}

Observa-se, na Tabela 13, que os segmentos consonantais labiais precedentes à pretônica média posterior - como se nota nos vocábulos $p[\mathrm{u}]$ demos, $b[\mathrm{u}]$ tando, $v[\mathrm{u}]$ ador e $m[u]$ rcego constituíram-se como os condicionamentos estruturais propiciadores à elevação vocálica.

Considerando o baixo número de ocorrências de elevação da pretônica média posterior precedida por uma vogal - duas ocorrências num total de 5 (cf. Tabela 10) -, por um segmento consonantal lateral - uma única ocorrência num total de 3 (cf. Tabela 10) - e por um segmento palatal - uma única ocorrência num total de 4 (cf. Tabela 12) -, constata-se que somente uma análise com um maior número de dados poderia confirmar ou infirmar o fato de tais contextos poderem atuar como condicionamentos à aplicação da regra de elevação vocálica na fala culta recifense.

Passa-se à análise do único contexto não-estrutural selecionado pelo VARBRUL como um condicionamento para a elevação das pretônicas médias posteriores.

TABELA 14

Elevação das médias orais posteriores em relação ao gênero (sexo) dos falantes recifenses

\begin{tabular}{c|c|c|c}
\hline $\begin{array}{c}\text { Gênero (sexo) } \\
\text { (Nível de significância:.000) }\end{array}$ & Ocorrências & $\begin{array}{c}\text { Frequência } \\
\text { (\%) }\end{array}$ & P.R. \\
\hline Feminino & $53 / 146$ & $36 \%$ & .65 \\
Masculino & $22 / 133$ & $17 \%$ & .34 \\
\hline
\end{tabular}


Com base na análise da Tabela 14, observa-se que os informantes do gênero feminino evidenciaram uma tendência a aplicar a regra de elevação da pretônica média posterior.

Contemplando os contextos estruturais (fonéticos) que favorecem a elevação das vogais médias orais em posição pretônica, observa-se que, na elevação de /e/ $\rightarrow$ [i], o timbre do segmento tônico (vogal alta) e o ponto de articulação do segmento precedente (palatal) constituem os condicionamentos à aplicação da regra variável de harmonização vocálica, ratificando os resultados de Leite \& Callou (2002) e de Yacovenco (1993). No que diz respeito à elevação $/ \mathrm{o} / \rightarrow[\mathrm{u}]$, verificou-se que, além do segmento vocálico alto na sílaba tônica, tem-se o modo de articulação do segmento precedente à pretônica (oclusiva), o modo de articulação do segmento subsequente à pretônica (fricativas, oclusivas e nasais) e o ponto de articulação do segmento precedente à pretônica (labial) como os condicionamentos estruturais da harmonização vocálica, em consonância com Leite \& Callou (2002) e Yacovenco (1993).

Para entender o grau de relevância do gênero e da faixa etária tanto nos processos de abaixamento quanto nos processos de elevação das pretônicas médias, passa-se à análise, na fala culta recifense, do nível de interferência de tais categorias sociais, ainda que o gênero só tenha sido selecionado pelo VARBRUL para a aplicação da regra variável de elevação das pretônicas médias.

\section{Aplicação das regras de abaixamento e de elevação das pretônicas médias em relação ao gênero e à faixa etária dos recifenses}

Ao observar a aplicação das regras de abaixamento e de elevação vocálicas, integrando o gênero (homem e mulher) à faixa etária (jovem, adulto e idoso) dos falantes, busca-se vislumbrar, com base na análise comparativa dos Gráficos 1-2 e 3-4, a contribuição de tais categorias sociais para a caracterização fonológica da fala recifense. 
Passa-se à análise do nível de produtividade da regra de abaixamento das pretônicas médias anterior e posterior, respectivamente, em relação ao gênero e à faixa etária dos recifenses.

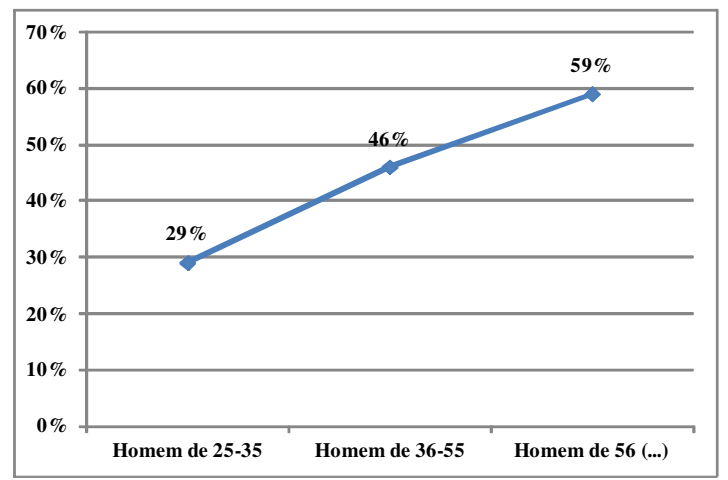

GRÁFICO 1

Abaixamento da pretônica média anterior em relação aos homens

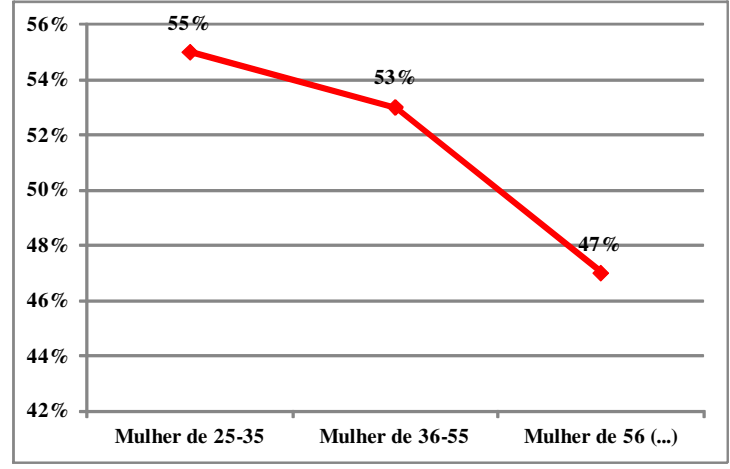

GRÁFICO 2

Abaixamento da pretônica média anterior em relação às mulheres

A partir da análise dos Gráficos 1 e 2, constata-se que os homens idosos e as mulheres jovens, com percentuais de uso de $59 \%$ e 55\%, respectivamente, para a aplicação da regra variável em análise, comportam-se como os que mais abaixaram as pretônicas médias anteriores. 


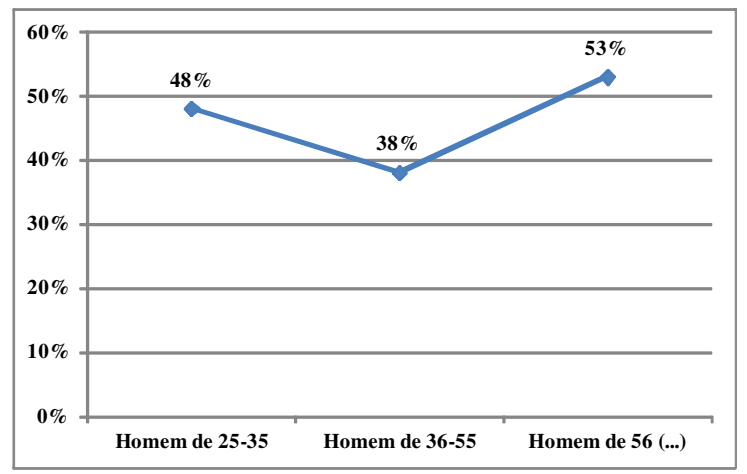

GRÁFICO 3

Abaixamento da pretônica média posterior em relação aos homens

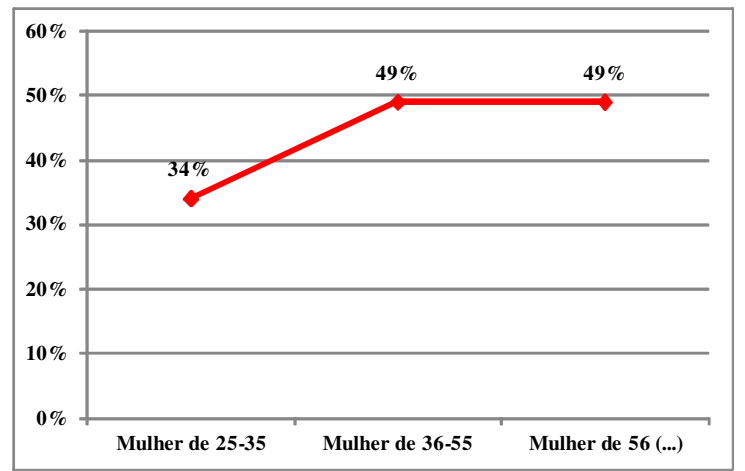

GRÁFICO 4

Abaixamento da pretônica média posterior em relação às mulheres

Ao examinar os Gráficos 3 e 4, têm-se os homens idosos com frequência de uso de $53 \%$ e as mulheres adultas e as idosas com índices percentuais de $49 \%$, respectivamente.

Em relação aos falantes da $1^{\text {a }}$ faixa etária (jovens), observase que as mulheres jovens (com 55\% de abaixamento da pretônica média anterior) representam as que mais abaixaram as vogais médias pretônicas, o que parece sugerir o encaminhamento da produtividade da regra variável de abaixamento vocálico alavancada pelos mais jovens. 
Os maiores índices percentuais de abaixamento vocálico distribuíram-se entre os homens idosos e as mulheres jovens, para a pretônica média anterior, e entre os homens idosos e as mulheres adultas e idosas, para a pretônica média posterior na fala culta de Recife.

Passa-se à análise comparativa dos Gráficos 5-6 e 7-8 a fim de vislumbrar a produtividade da regra de elevação das pretônicas médias anterior e posterior, respectivamente, em relação ao gênero e à faixa etária dos recifenses.

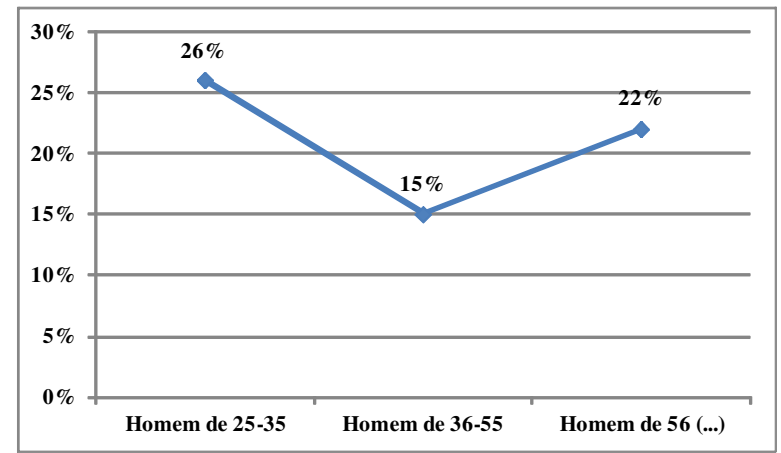

GRÁFICO 5

Elevação da pretônica média anterior em relação aos homens

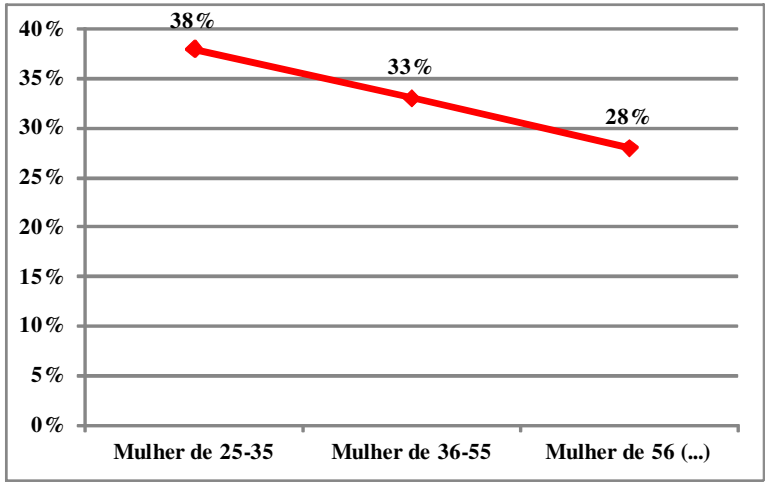

GRÁFICO 6

Elevação da pretônica média anterior em relação às mulheres 
Ao analisar comparativamente os Gráficos 5 e 6, verificase que os homens e as mulheres jovens, com frequências de uso de $26 \%$ e $38 \%$, respectivamente, apresentam-se mais propensos a elevar a pretônica média anterior. Constata-se ainda que as mulheres idosas e as mulheres adultas, com índices percentuais de $28 \%$ e $33 \%$, respectivamente, elevaram mais as pretônicas médias anteriores do que os homens adultos e os homens idosos.

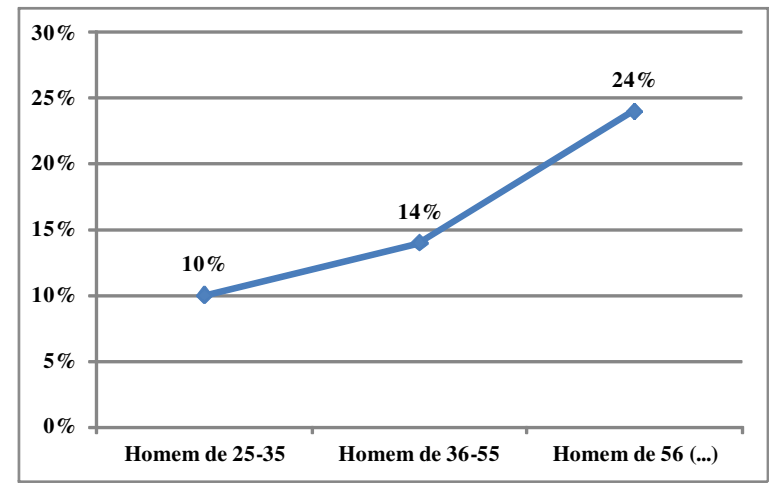

GRÁFICO 7

Elevação da pretônica média posterior em relação aos homens

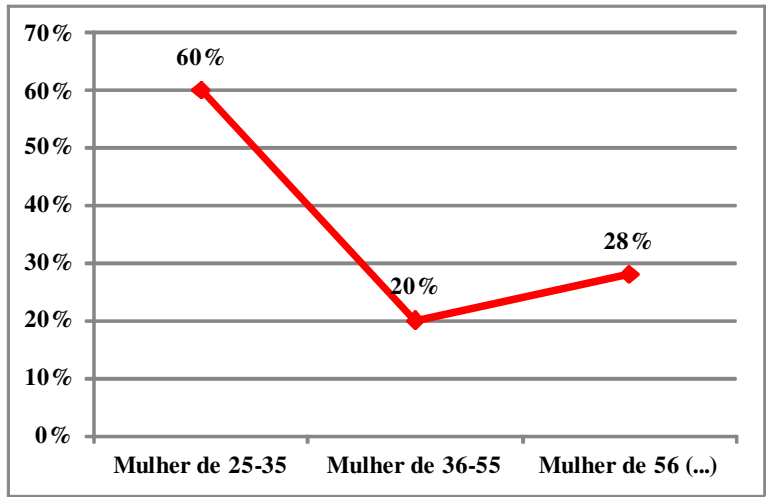

GRÁFICO 8

Elevação da pretônica média posterior em relação às mulheres 
Os Gráficos 7 e 8 evidenciam os homens idosos e as mulheres jovens, com frequências de uso de $24 \%$ e $60 \%$, respectivamente, como os que mais altearam a pretônica média posterior.

A regra de elevação vocálica apresenta-se com maior frequência de uso entre as mulheres jovens, com frequências de uso de $38 \%$ e $60 \%$ para as pretônicas médias anteriores e posteriores, respectivamente. $\mathrm{O}$ fato de as mulheres jovens apresentarem percentuais mais altos de aplicação da regra de elevação vocálica pode sugerir que sejam mais inovadoras, em consonância com as considerações de Leite \& Callou (2002, p.42), por tornarem produtivas "as variantes típicas da geração mais nova".

\section{Considerações finais}

Tendo em vista as realizações flutuantes do fonema

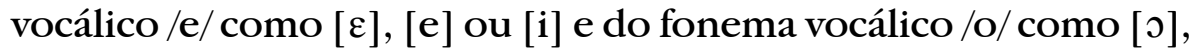
[o] ou [u], delineou-se um quadro de variação, predominando a realização aberta das pretônicas médias na fala culta de Recife. Vogeley, Hora \& Aguiar (2011), ao analisarem o comportamento variável das médias pretônicas, no processo de aquisição vocálica de crianças da cidade de Recife, comprovam o pressuposto de que "a variação também integra o processo de aquisição" (ROBERTS, 2002, apud VOGELEY, HORA \& AGUIAR, 2011, p. 60), uma vez que identificaram um sistema de variação no qual prevaleceu a variante aberta das médias pretônicas entre as crianças recifenses. A elevação vocálica mostrou-se como um processo de variação estável, visto que se trata de uma regra existente desde o século XV, segundo Révah (1958), conservando um baixo índice de aplicação no PB. Em suma, a análise dos contextos estruturais que subsidiaram a aplicação das regras de abaixamento e de elevação para as vogais médias pretônicas permite interpretar as tendências assimilatórias como as principais responsáveis por esses padrões variáveis no PB. 
No que diz respeito ao abaixamento vocálico, ao comparar os resultados desta análise quantitativa $-47 \%$ para Recife - com os de Silva (1998) para a cidade de Salvador - $60 \%-$, com os de Callou et al. (1995) para a cidade do Rio de Janeiro - 5\% -, e também com os de Viegas \& Cambraia (2011) - 0\%, 4,1\%, 51,8\% para, respectivamente, os municípios mineiros de Ouro Branco, Piranga e Machacalis -, observa-se que a cidade de Salvador, o município mineiro de Machacalis (Vale do Mucuri) e a cidade de Recife apresentaram as maiores frequências de uso da regra variável abaixamento vocálico. Considerando o padrão de abertura ter prevalecido em Machacalis (VIEGAS \& CAMBRAIA, 2011, p. 38), também se interpretou que tal município assumiria a área de falar baiano em consonância com a delimitação proposta por Nascentes (1953) e por Zágari (1998). Nesse sentido, parece confirmar-se a linha demarcatória traçada por Nascentes (1953) que caracteriza os falares do norte do Brasil como os que estão mais propensos a realizar as vogais pretônicas médias como vogais abertas (LEITE \& CALLOU, 2002, p. 40).

Em relação à aplicação da regra de elevação vocálica, ao confrontar os resultados desta análise quantitativa $-27 \%$ para Recife -, com os de Silva (1998) para Salvador - 25\% -, com os de Bisol (1981) para Porto Alegre - 22\% -, com os de Carmo (2012) para o noroeste paulista - 13\% -, com os de Callou et al. (1995) para o Rio de Janeiro - 32\% - e com os de Viegas \& Cambraia (2011) - 16,7\%, $27 \%$ e $16,5 \%$ - para os municípios mineiros de Ouro Branco, Piranga e Machacalis, respectivamente, verifica-se que os falantes cultos cariocas, recifenses e piranguenses apresentaram-se como os que mais elevaram as vogais médias em posição pretônica.

Ao conjugar o gênero (sexo) com a faixa etária dos informantes em relação à aplicação das regras variáveis de abaixamento e de elevação vocálicas, verificou-se que os homens idosos abaixaram mais as pretônicas médias anteriores e posteriores, com frequências de uso de 59\% e 53\%, respectivamente. Com relação à elevação vocálica, observa-se que as mulheres jovens elevaram mais tanto as pretônicas médias anteriores - 38\% -, 
quanto às pretônicas médias posteriores - 60\%. Vê-se, portanto, que parece não haver uma tendência de perda da produtividade das regras variáveis em análise, uma vez que o abaixamento é a regra que predomina no dialeto culto de Recife (no nordeste do Brasil) e a elevação vocálica, apesar do seu baixo índice de aplicação, é ainda mais cultivada entre as mulheres jovens, o que parece assinalar uma tendência linguística mais inovadora.

\section{Referências}

BISOL, L. Harmonização vocálica: uma regra variável. Tese (Doutoramento em Linguística e Filologia) - Faculdade de Letras, Universidade Federal do Rio de Janeiro, Rio de Janeiro, 1981.

CALLOU, D. et al. Um problema na fonologia do português: variação das vogais pretônicas. In: PEREIRA, C. da C.; PEREIRA, P. R. D. (Org.). Miscelânia de estudos linguísticos, filológicos e literários in memoriam Celso Cunha. Rio de Janeiro: Nova Fronteira, 1995. p. 59-70.

CARMO, M. C. As vogais médias pretônicas dos verbos na variedade do noroeste paulista e o processo de harmonização vocálica. In: LEE, S. H. (Org.). Vogais além de Belo Horizonte. Belo Horizonte: Faculdade de Letras da Universidade Federal de Minas Gerais, 2012. p. 132-147.

LABOV, W. Padrões sociolinguísticos. São Paulo: Parábola, 2008. [1. ed. ingl., 1972].

LEITE, Y.; CALLOU, D. Como falam os brasileiros. Rio de Janeiro: Jorge Zahar, 2002.

NASCENTES, A. O linguajar carioca. Rio de Janeiro: Simões, 1953.

RÉVAH, I. S. L' évolution de la prononciation au Portugal et au Brésil du XVI ${ }^{\mathrm{e}}$ siècle à nos jours. In: CONGRESSO BRASILEIRO DE LÍNGUA FALADA NO TEATRO, 1, Bahia, 5-9 setembro 1956. Anais... Rio de Janeiro: MEC, 1958. p. 387-402.

ROBERTS, J. Child language variation. In: CHAMBERS, J.; TRUDGILL, P; SCHILLING-ESTES, N. (Org.). The handbook of language variation and change. Oxford: Blackwell, 2002 apud VOGELEY, HORA \& AGUIAR (2011). 
SANKOFF, D. Variable rules. In: AMMON, U. et al. (Ed.). Sociolinguistics: an international handbook of the science of language and society. Berlin/New York: Walter de Gruyter, 1988. p. 984-998.

SILVA, M. B. da. As pretônicas no falar baiano: a variedade culta de Salvador. Tese (Doutoramento em Língua Portuguesa) - Faculdade de Letras, Universidade Federal do Rio de Janeiro, Rio de Janeiro, 1998.

VIEGAS, M. do C.; CAMBRAIA, C. N. Vogais médias pretônicas no português brasileiro: contrastando passado e presente. In: VIEGAS, M. C. (Org.). Minas é plural. Belo Horizonte: Faculdade de Letras da Universidade Federal de Minas Gerais, 2011. p. 13-43.

VOGELEY, A. C.; HORA, D. da; AGUIAR, M. A. de M. Aquisição e variação das vogais médias pretônicas. Diadorim: Revista de Estudos Linguísticos e Literários, Rio de Janeiro, n. 8, p. 59-78, 2011.

ZÁGARI, M. R. L. Os falares mineiros: esboço de um atlas linguístico de Minas Gerais. In: AGUILERA, V. (Org.). A geolinguística no Brasil: caminhos e perspectivas. Londrina: UEL, 1998. p. 31-54.

YACOVENCO, L. C. As vogais médias pretônicas na fala culta carioca. Dissertação (Mestrado em Língua Portuguesa) - Faculdade de Letras, Universidade Federal do Rio de Janeiro, Rio de Janeiro, 1993.

WEINREICH, U.; LABOV, W.; HERZOG, M. I. Empirical foundations for a theory of language change. In: LEHMANN, W.; MALKIEL, Y. (Ed.). Directions for historical linguistics. Austin: University of Texas Press, 1968. p. 95-195.

Recebido para publicação em 30 de agosto de 2012 Aprovado em 5 de novembro de 2012 